\title{
Genogroup I picobirnavirus in diarrhoeic foals: Can the horse serve as a natural reservoir for human infection?
}

\author{
Balasubramanian Ganesh ${ }^{1 *}$, Krisztian Banyai $^{2}$, Gisela Masachessi $^{3}$, Zornitsa Mladenova ${ }^{4}$, Shigeo Nagashima ${ }^{5}$, \\ Souvik Ghosh ${ }^{6}$, Seegekote Mariyappa Nataraju', Madhusudhan Pativada', Rahul Kumar ${ }^{1}$, Nobumichi Kobayashi ${ }^{6}$
}

\begin{abstract}
Picobirnaviruses (PBV) are small, non-enveloped viruses with a bisegmented double-stranded RNA genome. In this study a PBV strain, PBV/Horse/India/BG-Eq-3/2010, was identified in the faeces of a 10 month old weaned female foal with diarrhoea in January 2010 from Kolkata, India. Surprisingly, sequence comparison and phylogenetic analysis of a short stretch of the RNA dependent RNA polymerase gene revealed close genetic relatedness (> 98\% nucleotide identity) to a human genogroup I PBV strain (Hu/GPBV1) detected earlier from the same part of India. Our observations together with earlier findings on genetic relatedness between human and animal PBV warrant further studies on zoonotic potential.
\end{abstract}

\section{Introduction, Methods and Results}

Picobirnaviruses (PBV) are small, non-enveloped viruses, with a bisegmented dsRNA genome. PBV exists as either a large genome profile (2.3 to $2.6 \mathrm{kbp}$ and 1.5 to $1.9 \mathrm{kbp}$ for the segments 1 and 2, respectively) [1-3] or small genome profile $(1.75 \mathrm{kbp}$ and $1.55 \mathrm{kbp}$ for the segments 1 and 2, respectively) $[4,5]$. The PBV capsid protein has two main domains and forms a simple, spherical 33-41 nm virion [6].

The genomic segment 1 of the prototype PBV strain, Hy005102 was found to encode two open reading frames (ORF1 and ORF2) [7]; ORF1 codes for a hydrophilic group of 224 amino acids of unknown function. ORF2 has 552 amino acids that encode the capsid protein. The smaller segment 2 has a single ORF of 534 amino acids encoding the viral RNA dependent RNA polymerase (RdRp). Recently, additional sequence information of full or nearly full genome segments has been made available in the public DNA databases for other human strains $[8,9]$ as well as a lapin [10] and a bovine PBV strain [11].

\footnotetext{
* Correspondence: ganeshvirologist@yahoo.co.in

'Division of Virology, National Institute of Cholera and Enteric Diseases (NICED), P-33, C.IT. Road, Scheme-XM, Beliaghata, Kolkata 700 010, West Bengal, India

Full list of author information is available at the end of the article
}

Historically, PBV were first detected in the faecal specimens of humans and free-living rats (Oryzomys nigripes) in 1988 from Brazil [1,12]. Thereafter, PBV were detected in human faeces [7-9,13-16] and in a wide range of animal species worldwide. Farm mammals such as pigs, calves, foals, lambs, avians such as chickens, free-living mammals, companion and zoo animals, a variety of wild birds and even snakes have been found to shed PBV with or without diarrhoea [10,11,17-26]. The lack of a consistent pattern in PBV detection concomitantly in healthy [27] and diarrhoeic individuals and animal species raises questions regarding the pathogenic potential of PBV, albeit they have been often implicated in opportunistic infections in immunocompromised patients [28-30].

The detection of the bisegmented dsRNA genome of PBV by polyacrylamide gel electrophoresis (PAGE) and silver staining [31], is one of the standard and reliable laboratory diagnoses. Broadly reactive primer pairs for RT-PCR [8] have served as an alternative to PAGE, for molecular detection and characterisation of PBV. These RT-PCR primers specifically amplify small fragments within the RdRp gene, and are also capable of differentiating 2 major PBV genogroups, genogroup I and genogroup II. These primer sets were utilised in the present study, where we report the detection and molecular
Ciomed Central

C 2011 Ganesh et al; licensee BioMed Central Ltd. This is an Open Access article distributed under the terms of the Creative Commons Attribution License (http://creativecommons.org/licenses/by/2.0), which permits unrestricted use, distribution, and reproduction in any medium, provided the original work is properly cited. 
characterisation of an equine picobirnavirus detected in a diarrhoeic foal. Further characterisation by sequencing and phylogenetic analyses revealed that this equine PBV strain belongs to genogroup I and clusters with an Indian human and some Hungarian porcine PBV strains.

Seven faecal specimens were collected from adult domestic horses and foals (Equus ferus caballus) with or without diarrhoea from Kolkata, India during January 2010 as part of an ongoing study on picobirnavirus infections (Table 1): two from foals, two from colts, and one each from a filly, a mare and a stallion. The age of hosts ranged from 9 to 72 months.

From $10 \%$ fecal suspensions, total RNA was extracted for PAGE and silver staining [14,31]. Subsequently, the viral RNA was amplified using the primers and algorithms described previously $[8,14]$. The amplicons were purified and sequenced in both directions. The algorithm of nucleotide sequence editing and phylogenetic analysis was done as previously described [14,15]. The nucleotide sequence of the foal PBV strain, PBV/Horse/ India/BG-Eq-3/2010, was deposited in the DNA database (accession no. DDBJ: AB598401).

Screening of faecal RNA extracts by PAGE gave negative results. (Similarly, RT-PCR assay using the primers [32] targeting the rotavirus VP4 and VP7 genes failed to detect the group A rotavirus). However, a single faecal specimen obtained from a 10 month old weaned female foal was found to be positive for genogroup I PBV by RT-PCR using the genogroup specific primer pairs [8]. Sequence analysis of the amplicon indicated the presence of genogroup I PBV strain. This PBV strain, PBV/ Horse/India/BG-Eq-3/2010, shared 70\% nt and 66\% aa identity with the prototype genogroup I PBV strain, 1CHN-97 and only about $24 \%$ aa similarity to the prototype genogroup II PBV strain, 4-GA-91.

The nucleotide identities along a $170 \mathrm{bp}$ stretch and the partial length deduced amino acid identity (given in parentheses) of gene segment 2 (stretch of 56 amino acids) between the equine genogroup I PBV strain (PBV/ Horse/India/BG-Eq-3/2010) detected in Kolkata, India and the related human and porcine PBV strains were compared (Additional file 1: Table S1). In general, similarity values fell in the same range as described for other genogroup I PBV strains in some recent studies [15] except for a single Indian (Kolkata) human PBV strain GPBV1 [15] (98\% nt identity) and a few Hungarian porcine PBV strains [3] Po/D4/C-5/Hun; Po/D4/C-1/Hun; $\mathrm{Po} / \mathrm{D} 6 / \mathrm{C}-19 / \mathrm{Hun}$; and Po/C6/C-17/Hun $(75-87 \% \mathrm{nt}$ identity). In addition, the deduced stretch of 56 amino acids of our equine PBV strain and the majority of genogroup I PBV strains showed that 16 amino acids were conserved (Additional file 2: Table S2).

The "proline" in aa position 13 (the position in the alignment used for comparison) is conserved in all the PBV strains analysed to date, whereas another proline residue in aa position 25 was conserved in all other species except in bovine PBV strain Bo/RUBV-P. Similarly, the "methionine" in aa position 30 was conserved in all but two PBV strains: the human strain VS-22 identified from the Netherlands and the bovine strain RUBV-P from India.

Subsequently, the phylogenetic tree was constructed with a cognate stretch of hitherto reported human, porcine, bovine, canine, murine and serpentine genogroup I PBV strains (Figure 1) based on partial amino acid sequence (56 amino acids) of genomic segment 2 . This analysis revealed that the PBV/Horse/India/BG-Eq-3/ 2010 strain showed very close evolutionary relatedness to the Indian (Kolkata) human PBV strain GPBV1 [15] (100\% aa identity) and a few Hungarian porcine PBV strains [17] Po/D4/C-5/Hun; Po/D4/C-1/Hun; Po/D6/C19/Hun; and Po/C6/C-17/Hun (77-84\% aa identity).

\section{Discussion}

PBV in horses has been reported earlier [18], however this is the first description of an equine PBV strain at the molecular level. Since, the number of samples taken for this study was very small, this proportion cannot be taken as an indication of prevalence or incidence of PBV infection or disease association in domestic horses in Kolkata, India. The length of the gene fragment used for characterisation of PBV strains was relatively short,

Table 1 Details of faecal specimens collected from domestic horses and foals in Kolkata, India during January 2010 and screening for rotavirus and picobirnavirus by PAGE and RT-PCR assay

\begin{tabular}{|c|c|c|c|c|c|c|c|c|}
\hline \multirow[t]{2}{*}{ SI. No. } & \multirow[t]{2}{*}{ Sample code } & \multirow[t]{2}{*}{ Age and Sex } & \multirow[t]{2}{*}{ Health status } & \multirow[t]{2}{*}{ Stool consistency } & \multicolumn{2}{|c|}{ PAGE Screening } & \multicolumn{2}{|r|}{ RT-PCR } \\
\hline & & & & & RV & PBV & $\mathrm{RV}$ & PBV \\
\hline 1. & BG-Eq-1 & $3 \mathrm{yr} / \mathrm{F}$ (Filly) & Healthy & Normal & - & - & - & - \\
\hline 2. & $B G-E q-2$ & 5 yr/F (Mare) & Diarrhoeic & Loose & - & - & - & - \\
\hline 3. & $\mathrm{BG}-\mathrm{Eq}-3$ & 10 m/F (Foal) & Diarrhoeic & Loose & - & - & - & (+) ve 201 bp GGl \\
\hline 4. & $\mathrm{BG}-\mathrm{Eq}-4$ & 3 yr/M (Colt) & Healthy & Normal & - & - & - & - \\
\hline 5. & $B G-E q-5$ & 6 yr/M (Stallion) & Healthy & Normal & - & - & - & - \\
\hline 6. & BG-Eq-6 & 9 m/M (Foal) & Healthy & Normal & - & - & - & - \\
\hline 7. & BG-Eq-7 & 3 yr/M (Colt) & Healthy & Normal & - & - & - & - \\
\hline
\end{tabular}




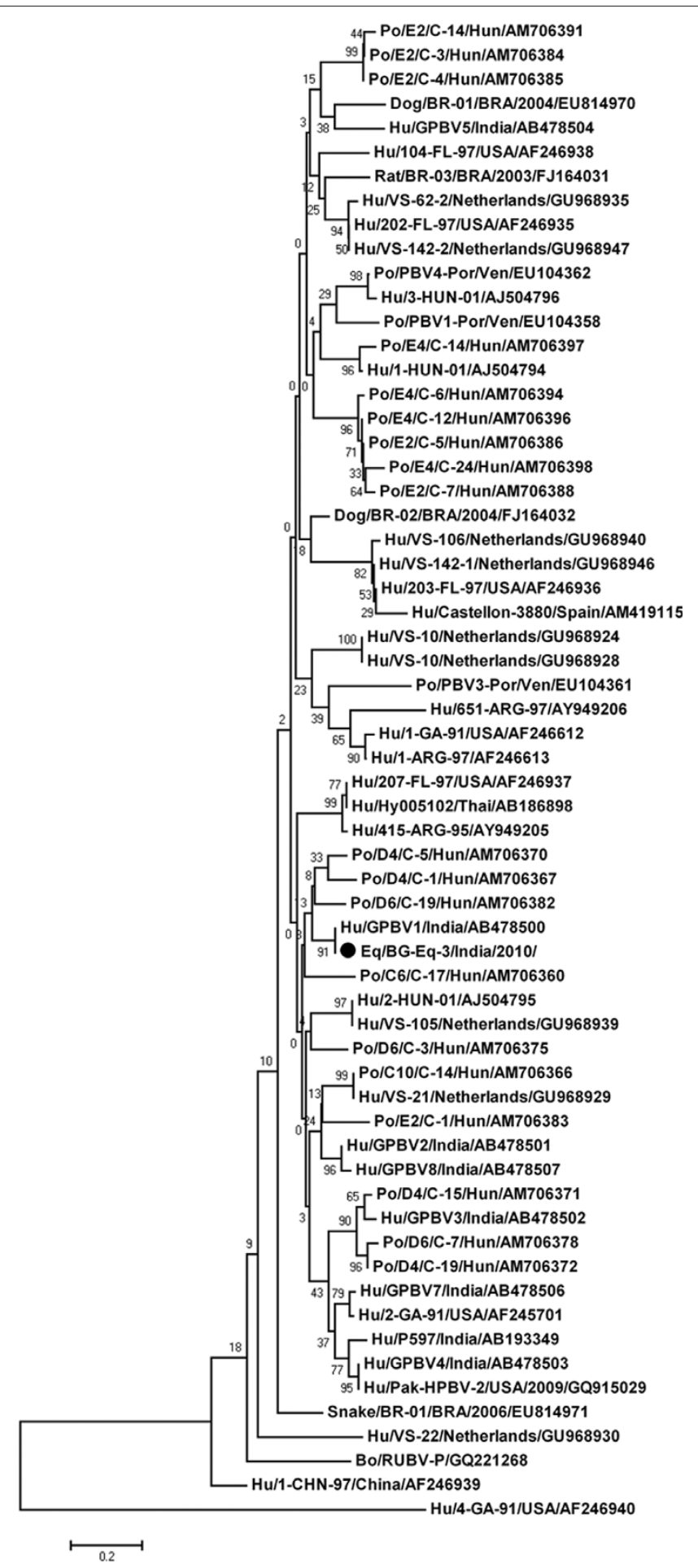

Figure 1 Phylogenetic tree showing the equine picobirnavirus strain (Genogroup I PBV/Horse/India/BG-Eq-3/2010) with cognate stretch of hitherto reported human, porcine, bovine, canine, murine and serpentine genogroup I PBV strains, based on partial amino acid sequence (56 amino acids (aa)) of genomic segment $\mathbf{2}$. The phylogenetic tree was constructed by the neighbor-joining method using the MEGA software (Version 4.1). Phylogenetic distances were measured by the Kimura two-parameter model, and the tree was statistically supported by bootstrapping with 1000 replicates. The genogroup I equine PBV strain BG-Eq-3 is denoted with a $\bullet$ symbol. The tree was rooted with cognate stretch of gene segment 2 of genogroup II prototype strain Hu/4-GA-91 (USA) defined as the outgroup strain. Abbreviations: Hu, Human; Po, Porcine; Bo, Bovine; Eq, Equine; ARG, Argentina; BRA, Brazil; Hun, Hungary; Thai, Thailand; USA, United States of America; Ven, 
thus conclusions on the evolutionary relationships between any two PBV may have limitations.

In addition, PBV have 2 genome segments and there is a theoretic possibility that genome segment reassortment may permit a large variety of the RdRp and capsid gene combinations to rise. Despite these shortcomings, this is the first study that provides evidence for genetic relationship between human and equine PBV strains.

One alternative to explain the close genetic relationship between these heterologous strains is the common exposure to PBV infection. PBV are commonly detected in communal sewage and surface waters [33], thus consumption of water contaminated with PBV may provide one way to acquire PBV by different host species. Another possible explanation is that one host may serve as source of infection for PBV to be transmitted to the other host. Whether horses or humans are the primary hosts for the particular strain that was found in this study and in another study [15] remains to be carefully investigated. Nonetheless, genogroup I PBV detected in pigs in parts of Europe [17] and Latin America [20] were closely related to human genogroup I PBV, suggesting the zoonotic potential of PBV strains.

Partial molecular characterisation and sequence analysis of human and animal PBV strains have shown that distinct sequence heterogeneity exists among PBV, implicating the importance of continued surveillance for newly emerging variants. Full genome analyses of the strains identified in the future may reveal the evolutionary mechanisms of PBV, pointing out the role of genetic drift and reassortment on the overall genomic architecture and to the possible traits implicated in the host range.

\section{Additional material}

Additional file 1: Table S1: Comparison of the percentage nucleotide identity and (amino acid identity given in parentheses) of Equine Picobirnavirus detected in a diarrhoeic foal in Kolkata, India with some of the hitherto reported human, porcine, canine, murine, bovine and serpentine picobirnaviruses.

Additional file 2: Table S2: Comparison of partial length deduced amino acid sequence of segment 2 of the Equine picobirnavirus detected in Kolkata with the hitherto reported human, porcine, canine, murine, bovine and serpentine picobirnaviruses.

\section{List of Abbreviations}

PBV: picobirnavirus; dsRNA: double-stranded RNA; kbp: kilo base pair; ORF: open reading frame; RdRp: RNA dependent RNA polymerase; PAGE: polyacrylamide gel electrophoresis; RT-PCR: reverse transcription-polymerase chain reaction; nt: nucleotide; aa: amino acid; Hu: human; Po: porcine; Bo: bovine; Eq: equine

\section{Acknowledgements}

We are grateful to Ms. Baby Shaw the owner, caretaker-cum-handler of the horses, who helped collect faecal specimens. We sincerely acknowledge the technical assistance of Tanaya Paul, Nibedita Chakraborty, Anwesha Sanyal, Bimal Bera, Khokon Sen, Mussaraf Hossain, and staff members of the Division of Virology for their whole-hearted support. The study was financially supported by the Indian Council of Medical Research (ICMR, Govt. of India), and Program of Founding Research Centre for Emerging and Reemerging Infectious Disease (Okayama University - NICED, India) from the Ministry of Education, Culture, Sports, Science and Technology, Japan. S.M.Nataraju, M. Pativada and R.Kumar were financially supported by fellowships from the Indian Council of Medical Research (ICMR, Government of India) and University Grants Commission (UGC), India, respectively.

\section{Author details}

'Division of Virology, National Institute of Cholera and Enteric Diseases (NICED), P-33, C.I.T. Road, Scheme-XM, Beliaghata, Kolkata 700 010, West Bengal, India. ${ }^{2}$ Veterinary Medical Research Institute, Hungarian Academy of Sciences, Hungaria krt. 21, 1143 Budapest, Hungary. ${ }^{3}$ Institute of Virology "Dr. J. M. Vanella", Faculty of Medical Sciences, National University of Cordoba, Cordoba, Argentina. ${ }^{4}$ Department of Virology, National Reference Laboratory of Enteroviruses, National Center of Infectious and Parasitic Diseases, 44A, Stoletov Blvd., Sofia 1233, Bulgaria. ${ }^{5}$ Division of Virology, Department of Infection and Immunity, Jichi Medical University School of Medicine, 3311-1 Yakushiji, Shimotsuke-shi, Tochigi-ken, 329-0498, Japan. ${ }^{6}$ Department of Hygiene, Sapporo Medical University School of Medicine, S-1 W-17, Chuo-Ku, Sapporo 060-8556, Japan.

\section{Authors' contributions}

GB: conceived of the study, study design and coordination, performed laboratory assays, drafted and revised the manuscript. KB: analysed and interpreted the data, drafted and revised the manuscript. MG; MZ: participated in preparation of illustrations, revising the draft for important intellectual content. NS; GS; KN: participated in the design of the study, drafting the manuscript. NSM; PM; KR: participated in the molecular assays and sequence analysis. All the authors read and approved the final manuscript.

\section{Competing interests}

The authors declare that they have no competing interests.

Received: 22 December 2010 Accepted: 17 March 2011

Published: 17 March 2011

\section{References}

1. Pereira HG, Fialho AM, Flewett TH, Teixeira JM, Andrade ZP: Novel viruses in human faeces. Lancet 1988, 2:103-104.

2. Pereira HG, de Araujo HP, Fialho AM, de Castro L, Monteiro SP: A virus with bi-segmented double-stranded RNA genome in guinea pig intestines. Mem Inst Oswaldo Cruz 1989, 84:137-140.

3. Ludert JE, Hidalgo M, Gil F, Liprandi F: Identification in porcine faeces of a novel virus with a bisegmented double stranded RNA genome. Arch Virol 1991, 117:97-107.

4. Bhattacharya R, Sahoo GC, Nayak MK, Rajendran K, Dutta P, Mitra U, Bhattacharya MK, Naik TN, Bhattacharya SK, Krishnan T: Detection of Genogroup I and II human picobirnaviruses showing small genomic RNA profile causing acute watery diarrhoea among children in Kolkata, India. Infect Genet Evol 2007, 7:229-238.

5. Gallimore Cl, Appleton H, Lewis D, Green J, Brown DW: Detection and characterisation of bisegmented double-stranded RNA viruses (picobirnaviruses) in human faecal specimens. J Med Virol 1995, 45:135-140.

6. Duquerroy S, Da Costa B, Henry C, Vigouroux A, Libersou S, Lepault J, Navaza J, Delmas B, Rey FA: The picobirnavirus crystal structure provides functional insights into virion assembly and cell entry. EMBO J 2009, 28:1655-1665.

7. Wakuda M, Pongsuwanna $Y$, Taniguchi K: Complete nucleotide sequences of two RNA segments of human picobirnavirus. J Virol Methods 2005, 126:165-169.

8. Rosen Bl, Fang ZY, Glass Rl, Monroe SS: Cloning of human picobirnavirus genomic segments and development of an RT-PCR detection assay. Virology 2000, 277:316-329.

9. van Leeuwen M, Williams MM, Koraka P, Simon JH, Smits SL, Osterhaus AD: Human picobirnaviruses identified by molecular screening of diarrhea samples. J Clin Microbio/ 2010, 48:1787-1794. 
10. Green J, Gallimore Cl, Clewley JP, Brown DW: Genomic characterisation of the large segment of a rabbit picobirnavirus and comparison with the atypical picobirnavirus of Cryptosporidium parvum. Arch Virol 1999, 144:2457-2465.

11. Ghosh S, Kobayashi N, Nagashima S, Naik TN: Molecular characterization of full-length genomic segment 2 of a bovine picobirnavirus strain: Evidence for high genetic diversity with genogroup I picobirnaviruses. J Gen Virol 2009, 90:2519-2524.

12. Pereira $H G$, Flewett $T H$, Candeias JA, Barth OM: A virus with a bisegmented double-stranded RNA genome in rat (Oryzomys nigripes) intestines. J Gen Virol 1988, 69:2749-2754.

13. Bányai K, Jakab F, Reuter G, Bene J, Uj M, Melegh B, Szücs G: Sequence heterogeneity among human picobirnaviruses detected in a gastroenteritis outbreak. Arch Virol 2003, 148:2281-2291.

14. Bhattacharya R, Sahoo GC, Nayak MK, Saha DR, Sur D, Naik TN, Bhattacharya SK, Krishnan T: Molecular epidemiology of human picobirnaviruses among children of a slum community in Kolkata, India. Infect Genet Evol 2006, 6:453-458.

15. Ganesh B, Nataraju SM, Rajendran K, Ramamurthy T, Kanungo S, Manna B, Nagashima S, Sur D, Kobayashi N, Krishnan T: Detection of closely related Picobirnaviruses among diarrhoeic children in Kolkata: Evidence of zoonoses? Infect Genet Evol 2010, 10:511-516.

16. Martínez LC, Giordano MO, Isa MB, Alvarado LF, Paván JV, Rinaldi D, Nates SV: Molecular diversity of partial-length genomic segment 2 of human picobirnavirus. Intervirology 2003, 46:207-213.

17. Bányai K, Martella V, Bogdán A, Forgách P, Jakab F, Meleg E, Bíró H, Melegh B, Szucs G: Genogroup I picobirnaviruses in pigs: evidence for genetic diversity and relatedness to human strains. J Gen Virol 2008, 89:534-539.

18. Browning GF, Chalmers RM, Snodgrass DR, Batt RM, Hart CA, Ormarod SE, Leadon D, Stoneham SJ, Rossdale PD: The prevalence of enteric pathogens in diarrhoeic thoroughbred foals in Britain and Ireland. Equine Vet J 1991, 23:405-409.

19. Buzinaro MG, Freitas PP, Kisiellius JJ, Ueda M, Jerez JA: Identification of a bisegmented double-stranded RNA virus (picobirnavirus) in calf faeces. Vet J 2003, 166:185-187.

20. Giordano MO, Martinez LC, Masachessi G, Barril PA, Ferreyra LJ, Isa MB, Valle MC, Massari PU, Nates SV: Evidence of closely related picobirnavirus strains circulating in humans and pigs in Argentina. J Infect 2011, 62:45-51.

21. Fregolente MC, de Castro-Dias E, Martins SS, Spilki FR, Allegretti SM, Gatti MS: Molecular characterization of picobirnaviruses from new hosts. Virus Res 2009, 143:134-136.

22. Gatti MS, de Castro AF, Ferraz MM, Fialho AM, Pereira HG: Viruses with bisegmented double-stranded RNA in pig faeces. Res Vet Sci 1989, 47:397-398.

23. Masachessi G, Martínez LC, Giordano MO, Barril PA, Isa BM, Ferreyra L, Villareal D, Carello M, Asis C, Nates SV: Picobirnavirus (PBV) natural hosts in captivity and virus excretion pattern in infected animals. Arch Virol 2007, 152:989-998.

24. Muñoz M, Alvarez M, Lanza I, Cármenes P: Role of enteric pathogens in the aetiology of neonatal diarrhoea in lambs and goat kids in Spain. Epidemiol Infect 1996, 117:203-211.

25. Pongsuwanna $Y$, Taniguchi $K$, Chiwakul M, Urasawa T, Wakasugi F, Jayavasu C, Urasawa S: Serological and genomic characterization of porcine rotaviruses in Thailand: detection of a G10 porcine rotavirus. J Clin Microbiol 1996, 34:1050-1057.

26. Wang Y, Tu X, Humphrey C, McClure H, Jiang X, Qin C, Glass Rl, Jiang B: Detection of viral agents in fecal specimens of monkeys with diarrhea. $J$ Med Primatol 2007, 36:101-107.

27. Zhang T, Breitbart M, Lee WH, Run JQ, Wei CL, Soh SW, Hibberd ML, Liu ET, Rohwer F, Ruan Y: RNA viral community in human feces: prevalence of plant pathogenic viruses. PLoS Biol 2006, 4:e3.

28. Giordano MO, Martinez LC, Rinaldi D, Gúinard S, Naretto E, Casero R, Yacci MR, Depetris AR, Medeot SI, Nates SV: Detection of picobirnavirus in HIV-infected patients with diarrhea in Argentina. J Acquir Immune Defic Syndr Hum Retrovirol 1998, 18:380-383.

29. González GG, Pujol FH, Liprandi F, Deibis L, Ludert JE: Prevalence of enteric viruses in human immunodeficiency virus seropositive patients in Venezuela. J Med Virol 1998, 55:288-292.
30. Grohmann GS, Glass RI, Pereira HG, Monroe SS, Hightower AW, Weber R, Bryan RT: Enteric viruses and diarrhea in HIV-infected patients. Enteric Opportunistic Infections Working Group. N Engl J Med 1993, 329:14-20.

31. Herring AJ, Inglis NF, Ojeh CK, Snodgrass DR, Menzies JD: Rapid diagnosis of rotavirus infection by direct detection of viral nucleic acid in silverstained polyacrylamide gels. J Clin Microbiol 1982, 16:473-477.

32. Iturriza-Gómara M, Kang G, Gray J: Rotavirus genotyping: keeping up with an evolving population of human rotaviruses. J Clin Virol 2004, 31:259-265.

33. Symonds EM, Griffin DW, Breitbart M: Eukaryotic viruses in wastewater samples from the United States. App/ Environ Microbiol 2009, 75:1402-1409.

doi:10.1186/1297-9716-42-52

Cite this article as: Ganesh et al:: Genogroup I picobirnavirus in diarrhoeic foals: Can the horse serve as a natural reservoir for human infection? Veterinary Research 2011 42:52.

\section{Submit your next manuscript to BioMed Central and take full advantage of:}

- Convenient online submission

- Thorough peer review

- No space constraints or color figure charges

- Immediate publication on acceptance

- Inclusion in PubMed, CAS, Scopus and Google Scholar

- Research which is freely available for redistribution

Submit your manuscript at www.biomedcentral.com/submit
C Biomed Central 